\title{
Design and validation of a supragenome array for determination of the genomic content of Haemophilus influenzae isolates
}

Rory A Eutsey ${ }^{1}$, N Luisa Hiller ${ }^{1,2}$, Joshua P Earl', Benjamin A Janto ${ }^{1,3}$, Margaret E Dahlgren ${ }^{1}$, Azad Ahmed ${ }^{1}$, Evan Powell ${ }^{1}$, Matthew P Schultz ${ }^{1}$, Janet R Gilsdorf ${ }^{4,5}$, Lixin Zhang ${ }^{4}$, Arnold Smith ${ }^{6}$, Timothy F Murphy ${ }^{7}$, Sanjay Sethi ${ }^{7}$, Kai Shen ${ }^{1,3,8}$, J Christopher Post ${ }^{1,3,8}$, Fen Z Hu${ }^{1,3,8^{*}}$ and Garth D Ehrlich ${ }^{1,3,8^{*}}$

\begin{abstract}
Background: Haemophilus influenzae colonizes the human nasopharynx as a commensal, and is etiologically associated with numerous opportunistic infections of the airway; it is also less commonly associated with invasive disease. Clinical isolates of $\mathrm{H}$. influenzae display extensive genomic diversity and plasticity. The development of strategies to successfully prevent, diagnose and treat $H$. influenzae infections depends on tools to ascertain the gene content of individual isolates.

Results: We describe and validate a Haemophilus influenzae supragenome hybridization (SGH) array that can be used to characterize the full genic complement of any strain within the species, as well as strains from several highly related species. The array contains 31,307 probes that collectively cover essentially all alleles of the 2890 gene clusters identified from the whole genome sequencing of 24 clinical $H$. influenzae strains. The finite supragenome model predicts that these data include greater than $85 \%$ of all non-rare genes (where rare genes are defined as those present in less than $10 \%$ of sequenced strains). The veracity of the array was tested by comparing the whole genome sequences of eight strains with their hybridization data obtained using the supragenome array. The array predictions were correct and reproducible for $\sim 98 \%$ of the gene content of all of the sequenced strains. This technology was then applied to an investigation of the gene content of 193 geographically and clinically diverse $\mathrm{H}$. influenzae clinical strains. These strains came from multiple locations from five different continents and Papua New Guinea and include isolates from: the middle ears of persons with otitis media and otorrhea; lung aspirates and sputum samples from pneumonia and COPD patients, blood specimens from patients with sepsis; cerebrospinal fluid from patients with meningitis, as well as from pharyngeal specimens from healthy persons.

Conclusions: These analyses provided the most comprehensive and detailed genomic/phylogenetic look at this species to date, and identified a subset of highly divergent strains that form a separate lineage within the species. This array provides a cost-effective and high-throughput tool to determine the gene content of any $\mathrm{H}$. influenzae isolate or lineage. Furthermore, the method for probe selection can be applied to any species, given a group of available whole genome sequences.
\end{abstract}

\footnotetext{
* Correspondence: fhu@wpahs.org; gehrlich@wpahs.org

${ }^{1}$ Center for Genomic Sciences, Allegheny Singer Research Institute, Allegheny General Hospital, 320 East North Avenue, 11th Floor, South Tower,

Pittsburgh, PA 15212, USA

${ }^{3}$ Department of Microbiology and Immunology, Drexel University College of Medicine, Allegheny Campus, Pittsburgh, PA, USA

Full list of author information is available at the end of the article
} 


\section{Background}

The sequencing of multiple strains from single bacterial species has revealed extensive genomic diversity within species [1-10]. This variability is observed as single nucleotide polymorphisms (allelic differences) as well as extensive differences in gene possession [11,12]. Studies of strain variability within species have led to the definition of the supragenome or pangenome as the full complement of genes encountered within a species $[1,11,13]$. The supragenome is composed of the core genome, i.e. the set of genes present in all the strains of the species, and the distributed genome (also known as dispensable or accessory genomes) i.e. genes present in only a subset of strains. In a few species, notably Mycobacterium tuberculosis, all strains have a highly conserved gene content such that $\sim 90 \%$ of genes are present in the core genome [7]. However, for the vast majority of bacterial species so examined the distributed genome is larger than the core. For example the genomic complements of the strains within the species Bacillus subtilis, Escherichia coli, and Gardnerella vaginalis are highly variable with the core genome making up only one third or less of the supragenome [7,14,15]. Differences in gene content across isolates account for differences in microbial functional activities, such as biofilm formation, pathogenic potential or antimicrobial resistance [12,16-19].

In addition to extensive diversity, comparative whole genome sequencing of multiple strains from the same species has revealed evidence of widespread horizontal gene transfer (HGT) among strains and even related species [4,20,21]. Gene exchange is a common and evolutionarily safe strategy, as opposed to point mutations, for bacteria to acquire novel gene combinations for adaption to environmental stresses, novel conditions, or new niches [12]. Thus, the species' supragenome represents the complete genetic repertoire from which individual isolates develop genomic variability as they exchange DNA. Knowledge of the naturally-occurring gene combinations is critically important for developing strategies for prevention, diagnosis, and treatment of bacterial infections considering that species-level information, such as are currently reported clinically, cannot distinguish between commensal and highly pathogenic strains of the same species.

Hybridization gene arrays provide a cost-effective and high-throughput means to investigate gene content. Most existing arrays, however, are based on the gene content of a single strain or a small number of reference strains with the addition of additional alleles for a few known highly variable loci, and thus, are not ideal to identify overall gene content from isolates of a diverse species. To overcome these limitations, we have developed a supragenome array capable of identifying over $85 \%$ of the non-rare $(\mathrm{V}>0.1)$ genes (those most likely to be clinically important). While this analysis is focused on a single species, the design strategy can be applied to any bacterial supragenome.

$H$. influenzae is a gram-negative bacterium that colonizes the human nasopharynx, as a commensal organism, but acts as an opportunistic pathogen upon gaining access/entry to other body sites. Routine immunization against the highly virulent serotype b form of $\mathrm{Hi}$ (Hib), initiated in the 1980's, has been very effective in reducing the incidence of $H$. influenzae sepsis, meningitis, and epiglotitis in the developed world [22]. In the postHib vaccine era, non-typeable $H$. influenzae (NTHi) continue to cause infections of the respiratory tree including otitis media (OM), conjunctivitis, sinusitis, pneumonia, and bronchitis especially in patients with chronic obstructive pulmonary disease (COPD); as well as playing a role in early colonization of the lower respiratory tracts of children with cystic fibrosis [23,24]. Over the last decade, Tsang and colleagues have documented an increase in the number of invasive NTHi [25-27]. Improved understanding of the bacterial factors that contribute to infection in various human niches is needed to design new strategies for their treatment or prevention.

\section{Methods}

\section{Whole genome sequencing and assembly}

A total of $24 \mathrm{H}$. influenzae whole genome sequences (WGS) were prepared or obtained for this study (Table 1). These included: 1) the nine NTHi strains previously sequenced using a 454 Life Sciences GS20 sequencer at the Center for Genomic Sciences (CGS) and used to develop the Finite Supragenome Model [2]; 2) ten additional CGS-sequenced NTHi strains prepared using one or more of the 454 Lifescience's technology platforms, including the GS20, FLX and Titanium as described [2,5,7] (Table 2); 3 ) the 4 NTHi genomes sequenced by others [2,28-30]; and 4) an Hib WGS (http://www.ncbi.nlm.nih.gov/genome/165?project_id=86647) [31]. All CGS-derived genomes were assembled using Newbler, as described [2].

\section{Identification of coding sequences for the 24 WGS strains}

The 24 genomes were submitted in parallel to the Rapid Annotations with Subsystems Technology (RAST) annotation service [37].

\section{Gene clustering algorithm}

A complete description of the algorithms used to create the gene clusters and subclusters is given by Hogg et al. [2]. Briefly, tfasty36 (Fasta package, version 3.6) was used for six-frame translation homology searches of all predicted proteins against all possible translations [38]. These results were parsed to select for all coding sequences that were above a threshold based on a selected identity and length. For grouping into clusters the threshold was set to 
Table $1 \mathrm{H}$. influenzae strains used in design of CGH array

\begin{tabular}{|c|c|c|c|c|c|c|c|c|}
\hline $\begin{array}{l}\text { Strain } \\
\text { name }\end{array}$ & $\begin{array}{l}\text { \# of } \\
\text { Clusters }\end{array}$ & $\begin{array}{l}\text { \# of Coding } \\
\text { sequences }\end{array}$ & $\begin{array}{l}\text { Genome } \\
\text { size }(\mathrm{mb})\end{array}$ & $\begin{array}{c}\mathrm{GC} \\
\text { Content(\%) }\end{array}$ & Clinical origin & Geographic origin & $\begin{array}{l}\text { GenBank } \\
\text { BioProject } \\
\text { numbers }\end{array}$ & Reference \\
\hline $22.1-21$ & 1967 & 2220 & 1.89 & 38.03 & Nasopharynx & Ann Arbor, Ml & PRJNA54389 & {$[32]$} \\
\hline $22.4-21$ & 1957 & 1975 & 1.85 & 38.04 & Nasopharynx & Ann Arbor, Ml & PRJNA16396 & {$[32]$} \\
\hline $22.1-24$ & 1973 & 1915 & 2.1 & 37.91 & Nasopharynx & Ann Arbor, Ml & PRJNA29373 & {$[32]$} \\
\hline 3655 & 1991 & 1951 & 1.88 & 38.02 & Blood & San Diego, CA & PRJNA54385 & {$[33]$} \\
\hline 6P18H1 & 2015 & 1952 & 1.91 & 38.1 & COPD & Buffalo, NY & PRJNA55127 & {$[34,35]$} \\
\hline 7P49H1 & 1897 & 1801 & 1.83 & 37.85 & COPD & Buffalo, NY & PRJNA55129 & {$[34,35]$} \\
\hline PITT AA & 2003 & 1973 & 1.88 & 38.12 & $\begin{array}{l}\text { COME, tube } \\
\text { replacement }\end{array}$ & $\begin{array}{l}\text { Children's Hospital, } \\
\text { Pittsburgh, PA }\end{array}$ & PRJNA54391 & {$[36]$} \\
\hline PITT BB & 1922 & 1892 & 1.83 & 37.99 & $\begin{array}{l}\text { COME, tube } \\
\text { replacement }\end{array}$ & $\begin{array}{l}\text { Children's Hospital, } \\
\text { Pittsburgh, PA }\end{array}$ & PRJNA16402 & CGS \\
\hline PITT CC & 1915 & 1892 & 1.82 & 37.98 & $\begin{array}{l}\text { COME, tube } \\
\text { replacement }\end{array}$ & $\begin{array}{l}\text { Children's Hospital, } \\
\text { Pittsburgh, PA }\end{array}$ & PRJNA18099 & CGS \\
\hline PITT DD & 1865 & 2900 & 1.78 & 37.89 & $\begin{array}{l}\text { COME, tube } \\
\text { replacement }\end{array}$ & $\begin{array}{l}\text { Children's Hospital, } \\
\text { Pittsburgh, PA }\end{array}$ & PRJNA16392 & CGS \\
\hline PITT EE & 1848 & 1870 & 1.81 & 38.04 & $\begin{array}{l}\text { COME, tube } \\
\text { replacement }\end{array}$ & $\begin{array}{l}\text { Children's Hospital, } \\
\text { Pittsburgh, PA }\end{array}$ & PRJNA58591 & {$[36]$} \\
\hline PITT GG & 1966 & 2097 & 1.89 & 38.01 & AOM, ottorhea & $\begin{array}{l}\text { Children's Hospital, } \\
\text { Pittsburgh, PA }\end{array}$ & PRJNA58593 & {$[36]$} \\
\hline PITT HH & 1948 & 1968 & 1.84 & 38.00 & $\begin{array}{l}\text { COME, tube } \\
\text { replacement }\end{array}$ & $\begin{array}{l}\text { Children's Hospital, } \\
\text { Pittsburgh, PA }\end{array}$ & PRJNA54393 & {$[36]$} \\
\hline PITT ॥ & 2057 & 2038 & 1.95 & 38.01 & AOM, ottorhea & $\begin{array}{l}\text { Children's Hospital, } \\
\text { Pittsburgh, PA }\end{array}$ & PRJNA54395 & {$[36]$} \\
\hline PITT J J & 2054 & 2293 & 1.97 & 38.03 & $\begin{array}{l}\text { COME, tube } \\
\text { replacement }\end{array}$ & $\begin{array}{l}\text { Children's Hospital, } \\
\text { Pittsburgh, PA }\end{array}$ & PRJNA18103 & CGS \\
\hline NML20 & 1838 & 1757 & 1.78 & 37.91 & Blood & Manitoba, Canada & PRJNA29375 & CGS \\
\hline R1838 & 1900 & 1813 & 1.82 & 38.01 & Blood & Papua New Guinea & PRJNA29377 & CGS \\
\hline R3021 & 2017 & 1977 & 1.88 & 37.96 & Nasopharynx & Seattle, WA & PRJNA54397 & [29] \\
\hline R393 & 2109 & 2175 & 2 & 38.15 & Sputum isolate & Malaysia & PRJNA29379 & CGS \\
\hline $\begin{array}{l}86- \\
028 \mathrm{NP}\end{array}$ & 2001 & 1925 & 1.91 & 38.15 & Nasopharynx & $\begin{array}{l}\text { Nationwide Childrens } \\
\text { Hospital, Columbus, OH }\end{array}$ & PRJNA58093 & {$[30]$} \\
\hline B10810 & 2044 & 2007 & 1.98 & 38.1 & Meningitis & United Kingdom & PRJNA86647 & Sanger \\
\hline R2846 & 1856 & 1803 & 1.82 & 38.02 & OME & Seattle, WA & PRJNA191921 & [29] \\
\hline R2866 & 2017 & 1929 & 1.93 & 38.08 & Blood & Seattle, WA & PRJNA161923 & [29] \\
\hline $\begin{array}{l}\text { RD } \\
\text { KW20 }\end{array}$ & 1892 & 1874 & 1.83 & 38.15 & $\begin{array}{l}\text { Laboratory } \\
\text { Strain }\end{array}$ & Columbia University & PRJNA57771 & {$[28]$} \\
\hline Avg & 1960.5 & 1999.875 & 1.8825 & 38.02 & $\mathrm{n} / \mathrm{a}$ & $\mathrm{n} / \mathrm{a}$ & $\mathrm{n} / \mathrm{a}$ & $\mathrm{n} / \mathrm{a}$ \\
\hline
\end{tabular}

$70 \%$ identity over $70 \%$ of the length of the shorter sequence. This single linkage algorithm will thus link together genes that are split in some strains but fused in others, so that it works well for dealing with gapped genome data. For grouping into subclusters, each gene in a cluster was compared to all other genes in the same cluster, and sequences with at least $95 \%$ identity over $95 \%$ of the length of the shorter sequence were grouped together.

\section{Design of the SGH array}

The SGH Array was designed using the WGS's of the 24 $H$. influenzae strains (that represented the set of all
$H$. influenzae genomes available at the time of construction). To design probes that recognize all of the known $H$. influenzae genes, the 47,997 coding sequences from these genomes were divided into 3100 clusters (Table 3). Each cluster contains sequences that are at least $70 \%$ identical over $70 \%$ of the length; this strategy groups together the orthologues across strains, as well as highly related genes within strains. Of these clusters, 1538 contained 38,184 sequences shared by all strains (core clusters); while 1562 contained 9,813 sequences present in a subset of 1 to 23 strains (distributed clusters). Many of these clusters contain multiple allelic variants, such that 
Table 2 Whole genome sequencing summary

\begin{tabular}{|c|c|c|c|c|c|c|}
\hline Strain name & \# 454 Contig & \# Contigs after closure & Coverage & \# Assembled reads & Avg read length & Platform \\
\hline PITT BB & 110 & 6 & 18.6 & 321633 & 106 & GS20 \\
\hline PITT CC & 43 & 13 & 20.5 & 347798 & 107.5 & GS20 \\
\hline PITT DD & 199 & 33 & 29.7 & 527939 & 100 & GS20 \\
\hline PITT נر & 71 & 11 & 23.5 & 434215 & 106.7 & GS20 \\
\hline NML20 & 41 & 18 & 24.9 & 409200 & 108.6 & GS20 \\
\hline R1838 & 42 & 18 & 26.7 & 446399 & 109 & GS20 \\
\hline R393 & 156 & 47 & 18.1 & 333127 & 108.6 & GS20 \\
\hline 22.1-24 & 270 & 17 & 17.6 & 342141 & 107.8 & GS20 \\
\hline $6 \mathrm{P} 18 \mathrm{H} 1$ & 50 & 28 & 30.9 & 233434 & 250 & FLX \\
\hline 7Р49H1 & 36 & 19 & 28.7 & 208570 & 250 & FLX \\
\hline
\end{tabular}

if probes were designed to only one representative sequence from each cluster they may not hybridize to all the alleles. To ensure the selection of probes that will hybridize to all known alleles, each cluster was further split into subclusters that grouped all sequences together that are $95 \%$ identical over $95 \%$ of the length of the shorter sequence. There were 4536 subclusters, of which 2350 corresponded to core sequences and 2186 corresponded to distributed sequences.

Once the coding sequences were organized into subclusters of highly related sequences, we used the longest sequence from each subcluster to create probes 60 bases in length. We designed 25267 different probes to 2008 of 2186 distributed subclusters (average of 12.5/subcluster), and 6040 probes to 2044 of the 2350 core subclusters (average of $2.95 /$ subcluster) (Table 3 ). This set covers 2890 of the 3100 clusters. A portion of the subclusters, 178 of the distributed and 306 of the core, were not amenable to probe design in most cases due to reasons such as short sequence, homopolymer runs, or only low complexity sequence. We also added 185 negative control probes, designed from S. pneumoniae sequences. All probes were placed on the final array in duplicate (Table 3, Additional file 1: Table S1, Figure 1).

\section{Hybridization array probe design}

$H$. influenzae specific: The longest sequence from each subcluster was used as a template to create probes of 60 bases in length. A set of 20 potential probes per subcluster was created by Nimblegen (Roche; Madison WI) using their software. The goal was to design $\sim 13$ probes corresponding to each distributed subcluster and $\sim 3$ probes corresponding to each core subcluster. Probes were ranked based on their specificity to clusters, specificity to subclusters, and probe-design parameters. To determine cluster and subcluster specificity each probe was compared using BLASTN to a database of all $H$. influenzae coding sequences from the 24 WGS's. The ideal probes have high scoring hits to all members of their subcluster, and no hits outside the cluster. Hits were ranked such that probes with the best rank contained high scoring hits to all members of the subcluster and lower scores to members of other subclusters. Next ranked were the probes with hits to members of the same subcluster as well as other subclusters. The worst score was to probes that only recognized a subset of the sequences in the same subcluster. Probes with similar subcluster specificity, were further ranked using the Nimblegen ranking algorithm, which accounts

Table 3 Gene clustering and probe design

\begin{tabular}{|c|c|c|c|c|c|c|c|}
\hline & \# Sequences & \# Clusters & $\begin{array}{l}\text { \# Clusters with } \\
\text { probes }\end{array}$ & \# Subclusters & $\begin{array}{l}\text { \# Subclusters } \\
\text { with probes }\end{array}$ & $\begin{array}{l}\text { \# Individual } \\
\text { probes }\end{array}$ & $\begin{array}{c}\text { \# Probes } \\
\text { (account duplication) }\end{array}$ \\
\hline $\begin{array}{l}\text { Distributed } \\
\text { Set }\end{array}$ & 9813 & 1562 & 1465 & 2186 & 2008 & 25267 & 50534 \\
\hline Core Set & 38184 & 1538 & 1425 & 2350 & 2044 & 6040 & 12080 \\
\hline All Clusters & 47997 & 3100 & 2890 & 4536 & 4052 & 31307 & 62614 \\
\hline $\begin{array}{l}\text { Negative } \\
\text { Controls }\end{array}$ & 185 & $\mathrm{n} / \mathrm{a}$ & $\mathrm{n} / \mathrm{a}$ & $\mathrm{n} / \mathrm{a}$ & $\mathrm{n} / \mathrm{a}$ & 185 & 370 \\
\hline $\begin{array}{l}\text { Nimblegen } \\
\text { Controls }\end{array}$ & $\mathrm{n} / \mathrm{a}$ & $\mathrm{n} / \mathrm{a}$ & $\mathrm{n} / \mathrm{a}$ & $\mathrm{n} / \mathrm{a}$ & $\mathrm{n} / \mathrm{a}$ & 9053 & 9053 \\
\hline Total & 48182 & 3100 & 2890 & 4536 & 4052 & 40545 & 72037 \\
\hline
\end{tabular}




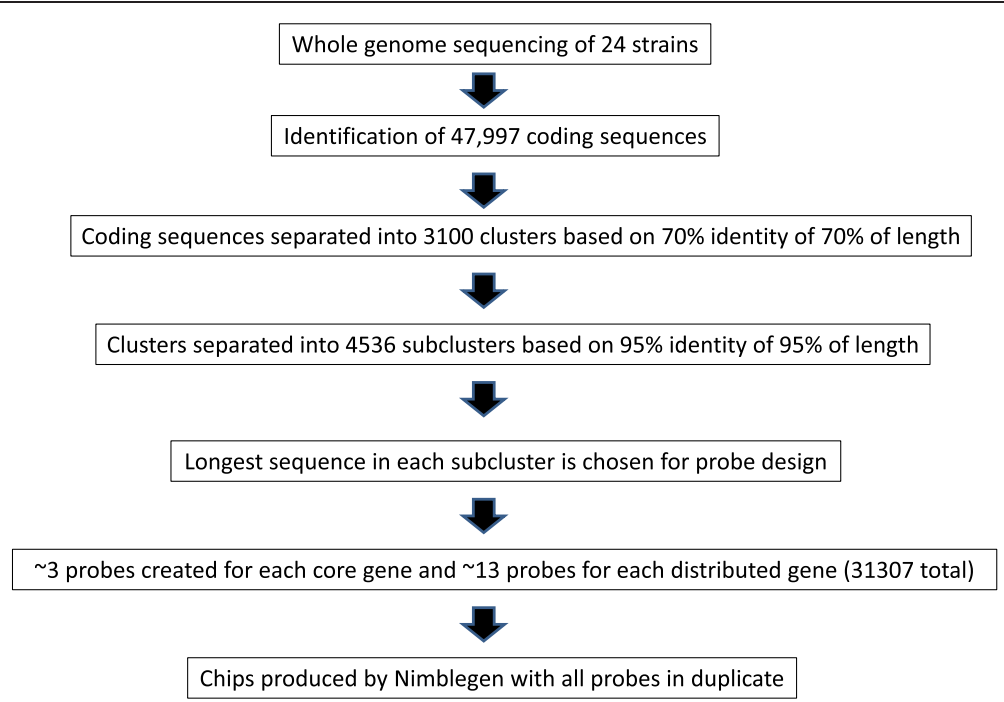

Figure 1 Schematic illustrating the stepwise strategy used to design the SGH array.

for uniqueness, distribution within the sequence (aimed at an even distribution), and probe manufacturing parameters. The negative controls were selected by using BLASTN to query $S$. pneumoniae genes from 44 strains [4] against a database of all the coding sequences from the $24 H$. influenzae genomes. The goal was to choose $S$. pneumoniae genes that have no homologues in $H$. influenzae, thus we selected a set of relatively long genes (> $500 \mathrm{bp}$ ) with only very low scoring hits (e-value above 1e-4). 185 sequences were selected, and one probe was designed to each one of these. Nimblegen generates a set of 9053 random control probes that serve as negative background hybridization controls. Alignment and tracking probes that bind to oligos added during hybridization allow the image analysis software to correctly determine probe grid positions as well as detect mixing between samples. These oligos were also used to determine the hybridization evenness over the entire probe covered area.

\section{DNA extraction for hybridization}

Overnight NTHi cultures were grown in $30 \mathrm{~mL}$ supplemented BHI broth and the bacteria were pelleted at $4000 \mathrm{rpm}$ for 5 minutes. Genomic DNA (gDNA) was extracted from the pellet using the standard 24:1 Chloroform/Isoamyl alcohol method and stored in $1 \mathrm{X}$ TE buffer [39]. Quality control was performed using the Nanodrop 1000, as well as running $\sim 1 \mu \mathrm{g}$ on a $1 \%$ TAE gel to observe molecular weight. If necessary, gDNA was treated a second time with RNaseA and Proteinase K, then reprecipitated to ensure sample purity [40].

\section{DNA labeling for hybridization}

gDNA samples were labeled using the Nimblegen One Color DNA Labeling Kit (NimbleGen Arrays User's
Guide: Gene Expression Arrays Version 6.0). Briefly, DNA samples were heated to $98^{\circ} \mathrm{C}$ for 10 minutes in the presence of $\mathrm{Cy} 3$ labeled random nonomers and then cooled rapidly. This reaction was then incubated at $37^{\circ} \mathrm{C}$ for 2 hours with dNTPs and Klenow fragment to complete labeling. Finally, the labeled DNAs were subjected to an isopropanol precipitation to get rid of unincorporated nucleotides and primers.

\section{Hybridization and washing}

Labeled DNA was prepared for hybridization by lypophilizing $2 \mu \mathrm{g}$ in a SpeedVac and resuspending in sample tracking solution (a different tracking solution is used for each sample). The sample was then mixed with the components of the Nimblegen Hybridization Kit (Hybridization buffer, component $\mathrm{A}$, and alignment oligo) and incubated at $95^{\circ} \mathrm{C}$ for 5 minutes before being loaded onto the NimbleGen microarray. The loading was carried out by pipetting the sample into a custom-built mixer that is adhered to the surface of the array. This assembly was then loaded into the Nimblegen Hybridization station and incubated for 18 hours. After incubation, arrays were washed using the NimbleGen Wash Buffer Kit and dried using the NimbleGen Slide Dryer.

\section{Array scanning}

Arrays were scanned using a Molecular Devices Axon GenePix 4200AL. Images were processed using Nimblegen NimbleScan software.

\section{Testing accuracy of $\mathbf{2 4}$ input strains}

The presence/absence profile for each of the 2890 gene clusters from the $H$. influenzae supragenome that were represented on the array was compared to the gene 
possession data from each of the 24 WGS'd strains as an objective means to determine the accuracy of the arrays. Presence/absence for the array was determined as described below in data analysis.

\section{Testing accuracy of CZ4126/02}

To establish whether the clusters identified by the array matched the whole genome sequencing data we used BLASTN. For each cluster a representative sequence from one of the original 24 genomes was selected. This representative was compared to the whole genome sequence of a 25th sequenced NTHi strain, CZ4126/02, GenBank accession number PRJNA189674 (Janto unpublished). If a hit was identified above the e-value threshold of $1 \mathrm{e}-20$, the cluster was considered present in the genome. If no hits were observed at this threshold, the cluster was considered absent.

\section{Data analyses}

Data were processed and normalized within arrays using a Robust Multichip Average (RMA) algorithm and quantile normalization using the NimbleScan software. Raw data were converted into cluster presence or absence by applying an expression threshold (set to $1.5 \mathrm{X}$ the median background value using a $\log _{2}$ scale). To determine intraslide consistency a Student $\mathrm{T}$ distribution analysis was used. A cluster was considered present if the signal for any of its subclusters was above the threshold and the p-value for the probe set was below 0.05. Note that the subclustering data cannot be used to confidently determine which allele is present, since small numbers of variations between a probe and sequence may still allow hybridization (the extent depends on the actual sequence).

\section{Tree building}

The 'ape' package in the ' $R$ ' environment was used to build a distance matrix based on the presence of clusters (as determined by SGH Array, or WGS when array data was not available) using the binary setting [41]. A tree was generated from the distance matrix using the nearest neighbor method and visualized with FigTree v1.3.1 (available at http://tree.bio.ed.ac.uk/software/figtree/) [42].

\section{Cost and time analysis}

The costs incurred per sample are approximately $\$ 110$. Samples can be processed in four days from culture to output.

\section{Results}

\section{Genome sequencing and annotation}

Twenty-four $H$. influenzae WGS's were utilized in the construction of a species-level supragenome hybridization (SGH) array (Table 1). At the start of this study
14 H. influenzae WGS's were available; the 13 described in Hogg et al. [2], which were a lab strain $(\mathrm{Rd})$, four nasopharyngeal isolates (86-028NP, R3021, 22.4-21, and 22.1-21), a blood isolate (R2866), and seven strains isolated from the middle ears of pediatric patients. Specifically, one acute otitis media isolate (3655), four chronic otitis media isolates (R2846, Pitt AA, Pitt EE, Pitt HH), and two ottorheic isolates (Pitt GG and Pitt II). There was also a type b strain (10810) sequence available through the NCBI microbial genome database [31]. To increase both the geographic and disease diversity of the sequenced strain set and to ensure that we had high coverage of all non-rare genes $(\mathrm{V} \geq 0.1)$ at the species level as predicted by the Finite Supragenome Model $[2,5]$, ten additional NTHi genomes were sequenced at the Center for Genomic Sciences (CGS) using 454 LifeSciences pyrosequencing (Table 2). These strains consisted of: four trans-tympanic isolates obtained from patients with chronic otitis media with effusion (COME) undergoing tube placement (PittBB, PittCC, PittDD, and PittJJ); two septic blood isolates (NML20 and R1838); three sputum isolates from patients with COPD (6P18H1, 7P49H1, and R393); and one additional NP isolate (22.1-24). Genome coverage levels ranged from $15.5-45.8$ and the number of contigs obtained by the Newbler assembler from the pyrosequencing data was between 36 and 270 for the 19 CGS-sequenced strains. Gap filling using PCR and Sanger sequencing of the resultant amplicons was performed as described [3] to reduce the number of contigs/genome to between 1 (genome closure was achieved for two strains PITT EE and PITT GG) and 59 (PITT HH) for the 19 CGS sequenced strains. The average $\mathrm{GC}$ content for the ten newly sequenced strains was $37.98 \%$ and their average genome size was 1.85 $\mathrm{Mb}$. These figures are nearly identical to the averages for the entire 24 strain set which averaged $38.02 \%$ GC, with an average genome length of $1.88 \mathrm{Mb}$. The final assemblies for the ten novel genomes have been deposited in GenBank, the accession numbers are: 22.1-24:PRJN A29373; 6P18H1: PRJNA55127; 7P49H1:PRJNA55129 ; PittBB:PRJNA16402; PittCC:PRJNA18099; PittDD:PRJN A16392; PittJJ:PRJNA18103; NML20:PRJNA29375; R1838: PRJNA29377, and R393:PRJNA29379.

\section{Identification of coding sequences for the $\mathbf{2 4}$ genomes} Using RAST [37] to annotate the 24 genomes we identified 47,997 coding sequences, with an average of 2000 per strain (Table 1). The annotations for the ten newly sequenced genomes were deposited in Genbank under the following accession numbers: 22.1-24:PRJNA29373; 6P18H1:PRJNA55127; 7P49H1: PRJNA55129;PittBB:PRJ NA16402; PittCC:PRJNA18099; PittDD:PRJNA16392; Pi 
ttJJ:PRJNA18103; NML20:RRJNA29375; R1838:PRJNA29 377 and R393:PRJNA29379.

\section{Coverage of the supragenome}

We applied the Finite Supragenome Model [2,5] to estimate the size of the supragenome based on the genomes from the 24 strains. Our model predicts a supragenome of 4547 clusters, 1485 core (32.67\%) and 3062 distributed. However, 1806 (39.73\%) of the distributed clusters are predicted to appear in less than $10 \%$ of strains and are considered rare genes, with the remaining 2741 clusters representing the distributed set present in at least $10 \%$ of strains. We extrapolate that the 2890 clusters represented on the array represent $63.5 \%$ of all $H$. influenzae clusters. Furthermore, the 2890 clusters include 2308 non-rare clusters, with the remaining 582 clusters being present in 2 or fewer of the 24 original strains. Thus $\sim 85 \%(2308 / 2741)$ of the non-rare genes from the species supragenome are represented on this array.

\section{Accuracy of the array}

To investigate the accuracy of the SGH array the possession profile for all 2890 clusters on the array was compared between the array output and the whole genome sequence (WGS) data for 7 of the 24 genomes used for the array design. The genomes used for comparison were: PittAA, NML20, 22.2-21, Hi7P49HI, R2846, R2866, and R1838 (Table 4). For the clusters represented on the array, we calculated: 1) the false negatives (those that were not captured by the SGH array, but are present in the WGS, represented in yellow in Figure 2); and 2) the false positives (those that were captured on the SGH array but are absent in the WGS, represented in orange in Figure 2). The WGS was considered the gold standard, although this may not always be the case since not all of these genomes are closed and thus contain gaps. It is likely that at least a subset of false positives represent the sequences within these gaps. On average there were 25 (1.44\%) false negatives and 19
(1.1\%) false positives/genome. These results are summarized in Table 4 and visualized in the CIRCOS diagram in Figure 2, where the matches between both methods are in gray, and the false positive and negative predictions in orange and yellow, respectively.

After construction of the array, the NTHi strain CZ4126/02 was also analyzed by both WGS and the SGH array (Table 4). Since its genomic sequence was not available when the array was designed, it served as an excellent test case to evaluate the accuracy of the array on new genomes. By analysis of the WGS it was determined that the array contained probes for 1702 of the CZ4126/02 clusters. Of these, 97\% (2805/2890) of the clusters on the array were correctly predicted. Thirty nine clusters detected by the arrays were missing in the WGS; these could be actual false positives and/or genes present in the contig gaps. Consistent with some of these SGH-positive/WGS-negative genes being present in the WGS gaps, is the fact that many of the WGSmissing genes are found in contiguous groups in other WGS strains (e.g. 10 of these genes are present as an uninterrupted linkage group in Hi6P18H1). Forty six genes did not hybridize to the array yet had at least a portion of the gene present in the CZ4126/02 WGS as determined by a BLAST comparison. Interestingly, though, in most of these cases only a section of the sequence (not the full sequence) was present in the WGS suggesting this is an upper estimate of the number of false negatives. Finally, four genes that are unique to CZ4126/02 are missing in all 24 other WGS strains. Since these rare genes were not known at the time of SGH array design, there are no probes to identify their presence and they must be considered false negatives.

\section{Reproducibility of technical replicates within and across SGH arrays}

The SGH Array was tested for reproducibility both between arrays and within the same array. Reproducibility within the same array was tested for strains 22.2-22,

Table 4 Comparison of SGH to Whole Genome Sequencing

\begin{tabular}{|c|c|c|c|c|c|}
\hline Strain & $\begin{array}{c}\text { No of clusters based on } \\
\text { supragenome analysis }\end{array}$ & $\begin{array}{l}\text { Clusters } \\
\text { represented on } \\
\text { chip }\end{array}$ & $\begin{array}{l}\text { Number in agreement } \\
\text { between WGS and CGH }\end{array}$ & $\begin{array}{c}\text { False negatives } \\
(\text { CGH -, WGS +) [\%] }\end{array}$ & $\begin{array}{c}\text { False positives } \\
(\mathrm{CGH}+, \text { WGS -)[\%] }\end{array}$ \\
\hline PittAA & 2003 & 1849 & 1803 & 46 [2.49\%] & 46 [2.49\%] \\
\hline NML20 & 1838 & 1688 & 1665 & 23 [1.36\%] & 11 [0.65\%] \\
\hline $22.1-21$ & 1967 & 1811 & 1786 & 25 [1.38\%] & 14 [0.77\%] \\
\hline HI7P49HI & 1897 & 1744 & 1724 & 20 [1.15\%] & 16 [0.92\%] \\
\hline R2846 & 1856 & 1708 & 1686 & 22 [1.29\%] & 20 [1.17\%] \\
\hline R2866 & 2017 & 1860 & 1837 & 23 [1.24\%] & 13 [0.70\%] \\
\hline R1838 & 1900 & 1748 & 1728 & 20 [1.14\%] & 15 [0.86\%] \\
\hline CZ4126-02 & & $1702^{*}$ & 1656 & 46 [2.7\%] & 39 [2.29\%] \\
\hline
\end{tabular}

* based on WGS of CZ4126-02, and not included in SGHChip design. 


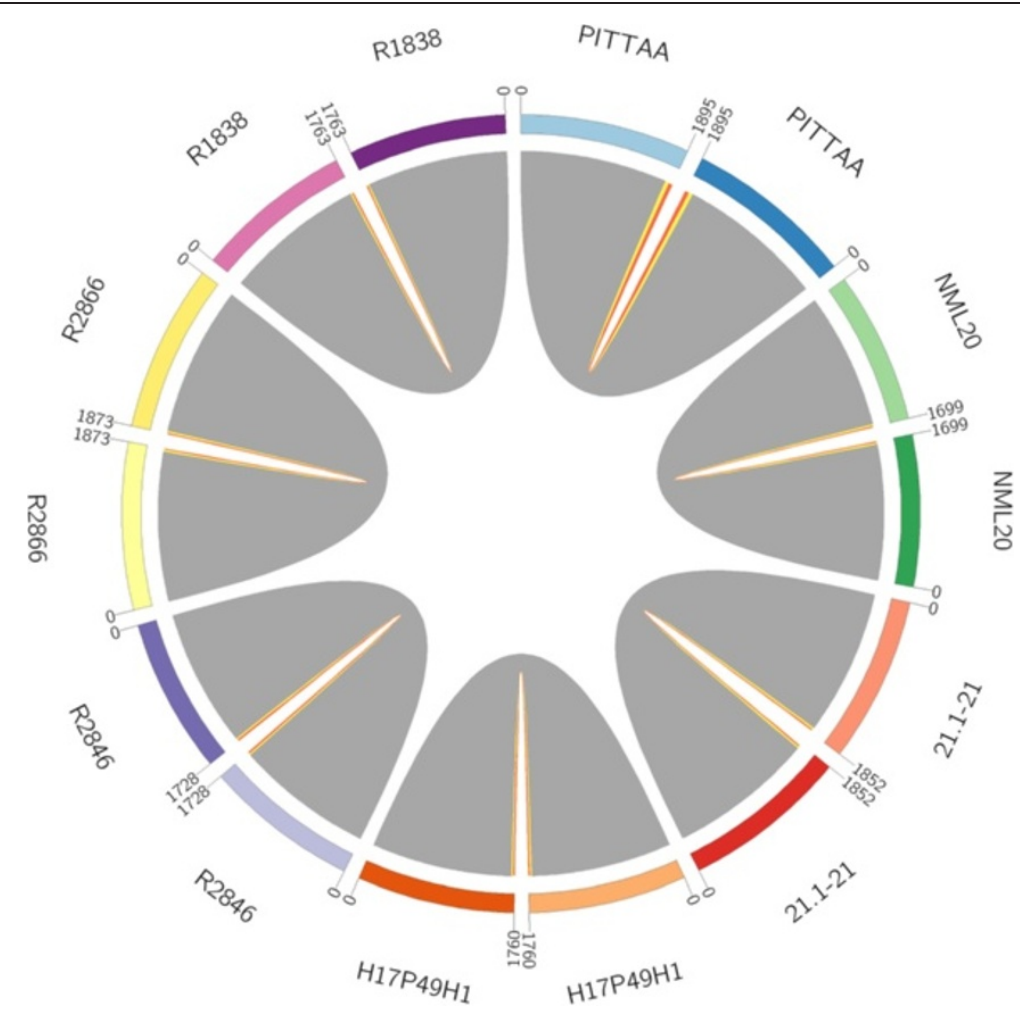

Figure 2 Comparison between WGS data and SGH array data, as represented by a CIRCOS diagram. Grey: gene clusters where both methods agree; yellow: negative on SGH array but positive for WGS; orange: positive on SGH array but negative for WGS. Paired numbers represent genes within each genome.

26.1-23, and 26.4-24 by comparing hybridization results between the duplicate probe sets as each array has two copies of all $H$. influenzae and negative control probes (Figure 3Ai,ii,iii). Clusters appearing in the upper right quadrant are predicted to be present in both data sets of a comparison. As expected these represent the majority of the dots as an average genome has 1956 clusters and the array represents 2890 clusters in total. Clusters appearing in the lower left quadrant are missing in both data sets, and correspond to a subset of the distributed genes. For the upper left and lower right quadrant the hybridization value is above the threshold in one data set, and below in the other. The $\mathrm{R}^{2}$-values for the bestfit line of the X/Y scatter of each probe set for all three strains are $>0.99$ suggesting very high fidelity of the probes within each array.

To investigate the reproducibility between SGH arrays, we used DNA isolated from the same three strains above (Figure 3Bi-iii). Each of these DNAs was subjected to separate labeling, hybridization, and analysis procedures for each of two SGH analyses. The number of clusters that yielded different possession profiles for the three strains 22.2-22, 26.1-23, and 26.4-24 respectively were 9, 18 , and 6 . Thus, the reproducibility of the data from the SGH arrays for these three strains was 99.69\%, 99.38\%, and $99.79 \%$ respectively. Note, that for a gene to be considered present, it must be above the threshold and the probe set must have a $\mathrm{p}$-value $<0.05$, thus there is not a perfect match between the thresholds illustrated in Figure 3 and the mismatched probes listed above.

\section{Analysis of the gene content of $210 \mathrm{H}$. influenzae strains}

We next determined the gene content of 186 geographically and clinically diverse NTHi strains from collections around the world using the validated SGH arrays (Additional file 1: Table S1). These data were used to construct a distance-matrix tree which shows the relative relatedness of all strains based on essentially whole genome gene possession data (Figure 4). The tree shows the relative distances among all 210 (24 WGS + 186 $\mathrm{SGH}$ ) genomically characterized $H$. influenzae strains. The 24 strains with WGS (colored blue in Figure 4) are distributed evenly around the tree indicating that they represent a broad sample of the species as intended. Surprisingly, of the 1538 clusters present in all 24 sequenced strains, only $678(47 \%)$ were found to be present in all 210 strains. This number would suggest that only $23 \%$ of the genome is core, whereas we had previously predicted that the core would make up $47 \%$ of the supragenome [2]. The reason for this finding is 

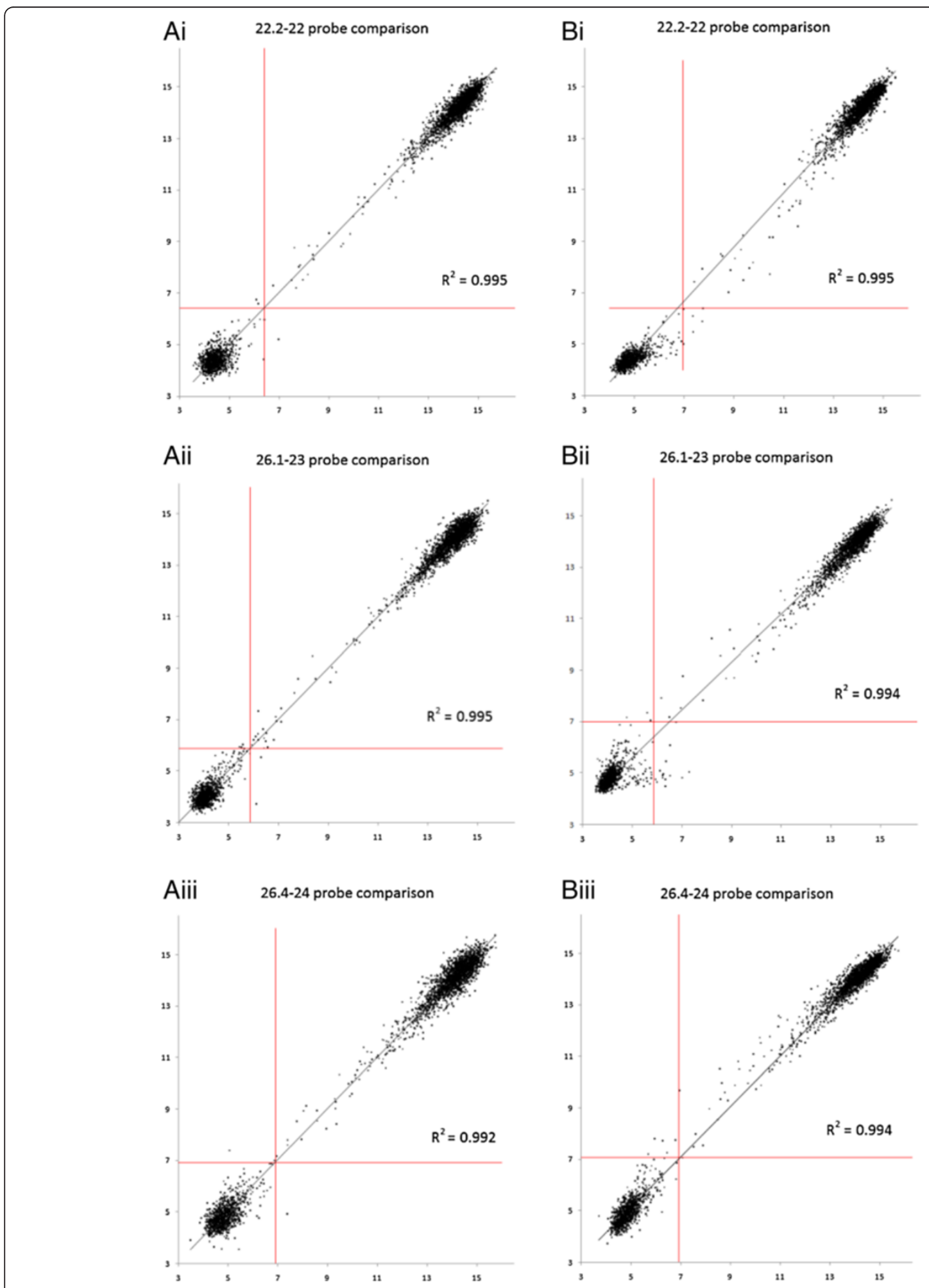

Figure 3 Reproducibility of SGH array. (A) X,Y Scatter plot of the hybridization values of duplicate probe sets for each cluster for a single sample within the same array. i: 22.2-22, ii: 26.1-23; iii: (B) X,Y scatter of the average hybridization values for each cluster of the same strains tested on separate arrays. i: 22.2-22, ii: 26.1-23; iii: 26.4-24. Red lines indicate thresholds used to define presence/absence of clusters. Hybridization values are displayed as $\log _{2}$. The subcluster with the highest value was chosen as the representative of the cluster. 


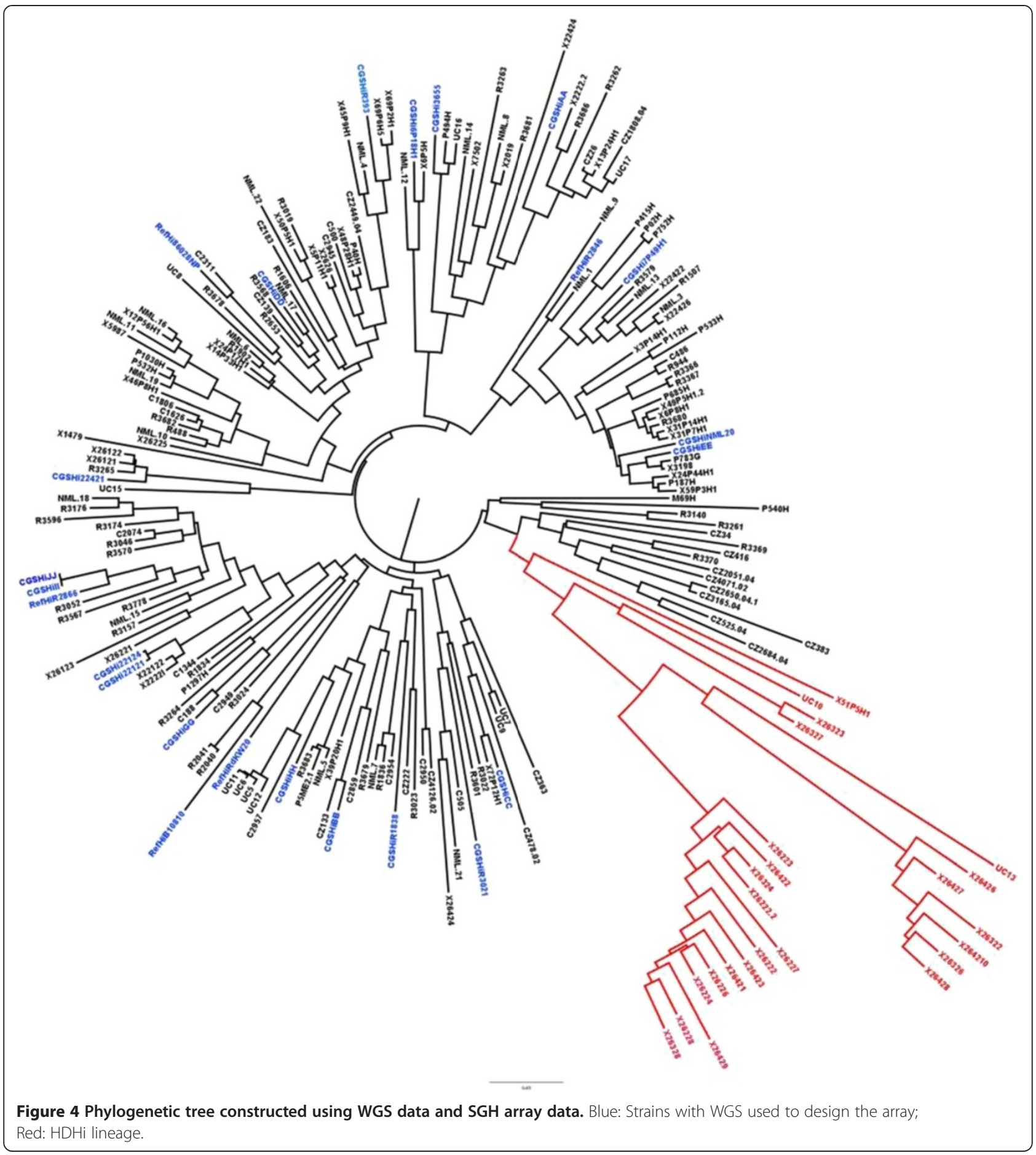

that a previously unidentified lineage of 24 highlyrelated strains are all missing many of the core genes (red in Figure 4). If this distinct lineage is removed from the analysis then the core genome includes 1049 clusters. Even in this reduced set of 186 strains, 3 other strains (CZ383, P533H and R3262; all carriage strains isolated from the nasopharynx), each in a different lineage, are each missing over 50 core clusters based on the 24 WGS strains. Thus, it appears that it is not uncommon for strains and lineages to arise via substantial genomic deletions. At this point we don't know if these strains have replaced these deleted genes with similar sized insertions or whether the genes are still present but have diverged in sequence such that they do not hybridize to probes on the SGH array. However, once these outliers are removed, $94.5 \%$ of the strains contain 
at least $98 \%$ of the 1425 clusters that were core in the 24 original strains. Thus the vast majority of these WGS core clusters are present in most of the strains. The extensive strain variability is visualized in Figure 5A and B; where each of the gene clusters is represented as a line radiating from the center, while each strain is represented as a concentric circle. Figure 5A illustrates the presence (blue) or absence (yellow) of each of the 2890 clusters for each of the 210 strains; where the 678 core genes are represented by radiating lines that are completely blue. Figure 5B represents only the 2212 distributed gene clusters. Thus, this figure illustrates how the distributed gene set ranges from very common (where the radiating line is mostly blue) to rare (where it appears as mostly yellow). Further, the 24 strains that are missing many core genes are displayed in the outermost circles, where their missing genes can be clearly visualized as lines that are blue in the innermost 186 circles and yellow in the 24 outer circles.

Each of the strains comprising the novel 24-strain divergent lineage, identified above, is missing between 82 and 274 genes previously considered core, suggesting that this lineage is either a subspecies or even a different species. We refer to this set of strains as the highly divergent $H$. influenzae (HDHi) (Table 5). Thus, the SGH array provides not only a high-throughput means to determine the gene content of any $H$. influenzae isolate, but also can serve as a tool to identify separate lineages and/or species. The classification of a strain as part of a separate species or lineage is based on the number of core genes represented in the new isolate. All $H$. influenzae strains share $\sim 50 \%$ of the supergenome (the core gene set). If an isolate is missing a significant percentage of the core gene set, it strongly suggests it is part of a different species or a distantly related lineage.

\section{Correlation between gene content and virulence potential}

The 186 NTHi strains used in this study were divided into virulent, commensal or unknown (Additional file 1: Table S1 and Additional file 2: Table S2). The virulent set consists of 117 strains isolated from sick patients, often from sites normally considered sterile, such as the blood, CSF, lung aspirates, and the middle ear. The commensal set consists of 65 strains isolated from the nasopharynx or throats of healthy individuals. Finally four strains were classified as unknown given lack of information or their lab origin (Rd KW20). The analysis was focused on NTHi, thus the $24 \mathrm{HDHi}$ strains (23 commensal and 1 virulent) were not considered in this analysis.

A Fisher Exact test of the commensal versus virulent strains identified 149 genes, which are significantly enriched in one set versus the other (Additional file 2: Table S2). Specifically 28 genes are more likely to be

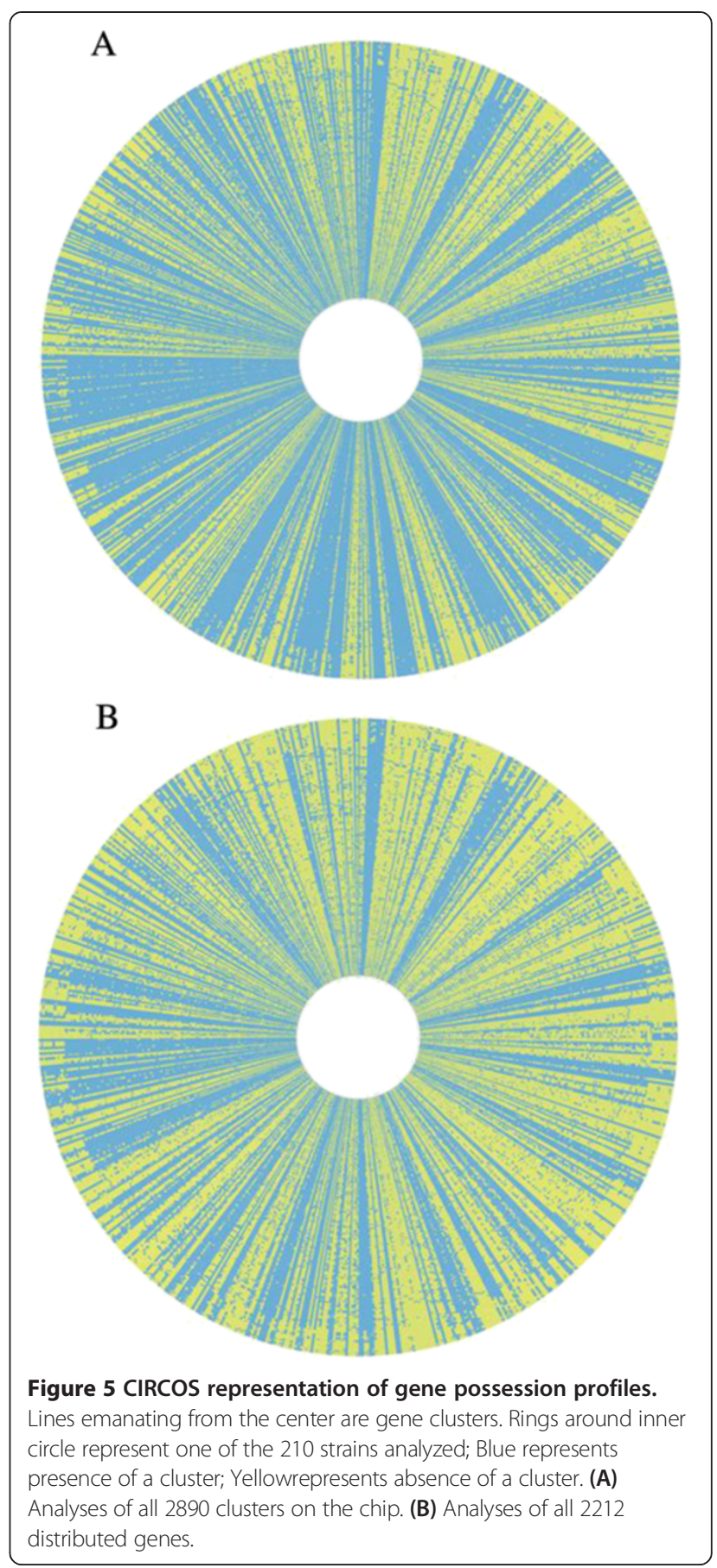

found in the virulent strains, while 121 were found to be enriched in the commensal strains. The high number of genes associated with commensal strains is consistent with the existence of functional categories that promote non-pathogenic growth. The annotation of "hypothetical gene" is the most common for both sets of these differentially possessed genes, accounting for nearly half (73/ 149) of the gene calls and indicating that there is much new biology to be learned with regard to the type of 
Table 5 HDHi strains

\begin{tabular}{|c|c|c|}
\hline Strain & $\begin{array}{l}\text { \# NTHI core genes } \\
\text { missing }\end{array}$ & $\begin{array}{l}\text { Meet criteria for } \\
\text { NTHi [43] }\end{array}$ \\
\hline $26.3-22$ & 274 & No \\
\hline UC13 & 274 & NA \\
\hline $26.4-210$ & 268 & No \\
\hline $26.3-26$ & 265 & No \\
\hline $26.4-28$ & 264 & No \\
\hline $26.4-26$ & 243 & No \\
\hline 26.4-29 & 234 & No \\
\hline $26.4-27$ & 225 & No \\
\hline $26.3-28$ & 218 & No \\
\hline $26.2-28$ & 212 & No \\
\hline $26.2-27$ & 206 & No \\
\hline $26.4-23$ & 201 & No \\
\hline $26.2-22$ & 198 & No \\
\hline $26.4-21$ & 196 & No \\
\hline $26.2-26$ & 194 & No \\
\hline $26.2-24$ & 193 & No \\
\hline $26.4-22$ & 161 & No \\
\hline $26.2-22.2$ & 160 & NA \\
\hline $26.2-23$ & 148 & No \\
\hline $26.3-24$ & 148 & No \\
\hline 51P5H1 & 105 & NA \\
\hline UC10 & 99 & NA \\
\hline $26.3-23$ & 97 & Yes \\
\hline $26.3-27$ & 82 & Yes \\
\hline
\end{tabular}

symbiotic relationship that develops between host and bacteria. The most common characterized functional category in the entire set of genes are the methylases, consistent with an important role for DNA modification in the regulation of virulence. There are 6 and 4 unique methylase clusters in the sets of genes enriched among the commensal and virulent strains, respectively (Additional file 3: Table S3). Similarly, different clusters of TRAP-type C4-dicarboxylate transport system also are associated with either the virulent or pathogenic strain set (Additional file 2: Table S2).

Among the 28 genes enriched in the pathogenic strains are the virulence associated toxin-antitoxin gene systems which are widespread amongst prokaryotes. These systems each consist of two genes, one of which codes for a toxin which cleaves single stranded RNA (via a PIN domain), and the other which codes for the antitoxin (part of the antitoxin-MazE superfamily) [43]. Other annotations of the pathogenic-enriched gene set include a highly conserved locus related to glycerol- 3-phosphate functional under anaerobic conditions. Finally, consistent with a role for surface proteins in host interactions; a putative surface protein is present in $25 \%$ of the virulent strains and only $12 \%$ of the commensals (it contains the Pfam DUF340 conserved domain which is of unknown function but contains a core of four predicted transmembrane regions).

The number of proteins associated with the commensal strains was much higher, corresponding to 121 genes. The gene cluster (representative member 6P18H1_1695) with the greatest p-value (1.3E-5) of all genes in either set is associated with $52 \%$ of commensals but only $20 \%$ of pathogenic strains (Additional file 2: Table S2). It is annotated as hypothetical, and does not contain any well characterized motifs. A search of the non-redundant database reveals homologues only in the Haemophilus genus $(H$. influenzae and $H$. haemolyticus). This set of genes also includes two putative transcriptional regulators, which are both short (under100 residues) and contain a helix turn helix domain (representative sequences are CGSHi22 421_177 and CGSHi22421_1968). It will be interesting to investigate whether these genes regulate a network of commensal-related coding sequences. Also, amongst the commensal gene set is the locus including the SlpA integrase that encodes the FxsA protein that affects phage T7 exclusion by the F plasmid [44], and a fimbrial subunit likely involved in adhesion (Pfam domain for Fimbrial proteins, representative CGSHi22121_609). Finally, there are at least three loci, each one with multiple adjacent proteins correlated with commensal strains, which contain two or more proteins annotated as phage-related proteins.

\section{Discussion}

The SGH array provides an inexpensive high-throughput means to analyze the genomic content of any $\mathrm{H}$. influenzae strain, by reporting on the possession of 2890 different gene clusters extracted from the WGS of 24 strains. Comparison of the WGS and SGH array data demonstrated the fidelity of the arrays. Comparisons of the hybridization values for the duplicated probe sets within a single array demonstrate their high reproducibility; and comparisons of the hybridization values among technical replicates (prepared with separate labeling, hybridizations, and scans) demonstrate high reproducibility across experiments.

We now have gene possession data on 210 Haemophilus influenzae strains, given the combination of the array data and WGS data. Analysis of the gene clusters from all strains reveals that only $23 \%(678 / 2890)$ of the supragenome is conserved across all strains. These data suggest that we are dealing with more than one species based on the Ahmed criteria [7] which states that if the addition of a single strain to what is an established and robust supragenome analysis (as we had for $H$. influenzae 
[2]) results in $>5 \%$ decrease in the core genome size then the last strain added is likely from a different species. If we exempt the $\mathrm{HDHi}$ and the other three core genome outliers, then $94.5 \%$ of strains contain $98 \%$ of all clusters. Based on our previous suggestion of using the core genome to define a species, we would argue that the differences observed for the HDHi are consistent with it forming a subspecies or even separate species. Twenty one of these novel strains were derived from longitudinal studies on two patients [43]. Analyses of these strains by Gilsdorf and colleagues for phenotypic characteristics routinely used to distinguish between $H$. influenzae and $H$. haemolyticus suggested that 19 out of 21 were not NTHi strains but instead met criteria for being classified as: 1) $H$. haemolyticus; 2) non-haemolytic $H$. haemolyticus; or 3 ) were chimeric strains with features of both $H$. influenzae and $H$. haemolyticus [46-48]. These strains were tested for the presence of iga, which encodes immunoglobulin A1 protease and for the presence of outer membrane protein P6 by reaction with 7F3 monoclonal antibody. They were also tested for hemolysis and porphyrin production. If they were positive for iga and P6 and negative for hemolysis and porphyrin, they were considered to be NTHi. Interestingly these two patients also carried strains in their pharynges that meet the criteria of $H$. influenzae, 14 of which were analyzed in this study using the SGH array. Three of the strains making up this novel lineage are from diverse sites, two were isolated in Australia from asymptomatic patients and one was isolated in Iowa from a patient with COPD. Two hypotheses can explain these results. First, this lineage is already widespread. Second, the bacteria in these patients were under similar fitness pressures to lose a particular set of genes. These hypotheses should be resolvable by whole genome sequence analysis which will reveal the sequence of alleles and any novel set of genes shared by these strains.

These data show the value of the SGH array for identifying core/distributed genes; grouping strains, and identifying new lineages/subspecies/species. It should be noted, however, that since the initial design did not include any representative strains from this novel lineage any lineage-specific genes will be missed by the array. Therefore, these results point us toward the sequencing of several representatives of this novel lineage and also determining their pathogenicity profile in our chinchilla model of otitis media and invasive disease $[16,49,50]$, as a recent report has identified $H$. haemolyticus as being etiologically associated with invasive disease [51].

This analysis revealed that many genes are enriched in commensal strains (121 genes) while others are more commonly found in virulent strains (Additional file 2: Table S2). Most enriched genes have unknown function, and thus should provide a rich source for targeted studies to characterize novel functional categories associated with virulence and protection from virulence. In contrast, we did not observe a correlation between geographical location and gene content. For example the ten strains isolated in Pittsburgh (PittAA-PittJJ) are widely distributed throughout the phylogenetic tree. Similarly, the three strains isolated from Papua New Guinea, although they all fall into the same general branch, do not cluster closely together suggesting they are more similar to strains isolated in other locations than they are to each other.

The data collected as part of this study are relative to Haemophilus $s p$, but the same strategy could be used to design and produce supragenome arrays for any species for which the majority of the supragenome has been sampled by sequencing a reasonable sized subset of strains. Many human pathogens and commensals have extensive genome diversity, such as Streptococcus pneumoniae, Escherichia coli, Garderella vaginallis, and Staphylococcus. aureus $[3,5,7,14]$. This diversity is also observed in many environmental and plant pathogens such as Pseudomonas aeruginosa, Xylella fastidiosus, and Bacillus cereus [52,53]. The number of core genes as a percent of total genes varies extensively across species. G. vaginalis, E.coli, and $B$. cereus have high strain diversity, with only $27 \%, 35 \%$, and $35 \%$ of total genes shared across all strains, respectively. In contrast, $M$. tuberculosis and B. anthracis have low strain diversity with $\sim 91 \%$ of the supra (pan) genome shared across all strains [7]. Different species generate novel strain combinations by transformation, conjugation and/or transduction. $H$. influenzae are naturally competent, and a genome wide analysis of recombinants generated in the laboratory demonstrated that homologous recombination is the main mechanism generating strain diversity [54].

We hypothesize that the extensive differences in the size of the core relative to the supragenome reflect both the age and the evolutionary history of the taxonomic domain being studied as well as the mechanisms used for HGT. In this manner, species that cause chronic infections in highly variable niches, such as the dynamic microbiome present in the human nasopharynx, are likely to have been selected to increase strain diversification. Whereas, it is tempting to speculate that B. anthracis, which causes highly acute disease, and is not associated with long-term survival in the human host does not require a large distributed genome because of its 'hit and run' pathogenic profile, the larger truth is that it is not a species unto itself, but rather is a pathogenic clade of $B$. cereus which has a very large distributed genome [55]. Thus, M. tuberculousis is the sole species characterized to date that has a very limited supragenome which may relate to its very recent evolutionary origins, i.e. it simply has not had time to diversify as much as older species. This array provides a powerful strategy for accessing genome content of diverse strains within a species or related species, and 
thus provides a high value tool for research on human health and environmental science.

\section{Conclusions}

The design and use of a custom SGH array based on a bacterial species supragenome modeled to contain the overwhelming majority ( $>85 \%)$ of non-rare genes provides a rapid and efficient means to screen large numbers of strains with regard to gene content $[2,3,5]$. These gene content data can then be parsed according to phenotype and subjected to statistical genetic tests to provide an unbiased method for identifying candidate genes for genotype-phenotype correlations. Thus, the method is independent of gene annotations and can point the way to useful new biology by identifying hypothetical genes of unknown function as being associated with given phenotypes. In the current analysis we employed this approach to identify candidate virulence genes for $H$. influenzae. Ongoing studies in our laboratories of two novel gene clusters that were targeted based, in part, on these technologies have been shown to indeed be virulence factors, and will be the subject of separate reports. Comprehensive SGH arrays also serve as useful tools for developing detailed visualizations and understandings of the genomic and phylogenetic relationships among strains, among groups of strains, and among closely related species. This aspect of the Haemophilus SGH described above revealed the existence of a novel clade within the species which we have termed the HDHi.

\section{Ethics statement}

We used only purified clonal bacterial isolates, and did not need to perform isolations from patient derived samples. Therefore no specific ethics approval or consent was necessary.

\section{Additional files}

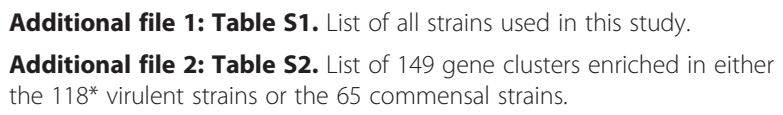

Additional file 3: Table S3. List of methylases enriched in either virulent or commensal strains.

\section{Competing interests}

GDE and FZH are authors on a US patent application (No. 61/233,642) "Use of Distributed Gene Data for Development of Strain-specific Bacterial Diagnostics"

\section{Authors' contributions}

RAE isolated DNA and carried out the array experiments, conceived the project and wrote the manuscript. NLH designed the SGH Array, conceived the project and wrote the manuscript. JPE created graphical representations of the data. BAJ isolated DNA and carried out the array experiments; conceived the project and wrote the manuscript. MED designed the SGH Array. AA isolated DNA and carried out the array experiments. EP isolated
DNA and carried out the array experiments. MPS created graphical representations of the data. JRG collected and contributed bacterial isolates. LZ collected and contributed bacterial isolates. AS collected and contributed bacterial isolates. TFM collected and contributed bacterial isolates. SS collected and contributed bacterial isolates. KS collected and contributed bacterial isolates. JCP conceived the project. FZH conceived the project. GDE conceived the project and wrote the manuscript. All authors read and approved the final manuscript.

\section{Acknowledgements}

The authors would like to thank Mary O'Toole for editing and preparing this manuscript. We would also like to thank Robert Wadosky, Raymond Tsang, Jennelle Kyd, Helena Zemlickova, Ana Lucia Andrade, and Michael Apicella for generously sharing their $\mathrm{H}$. influenzae strains. This work was supported by funding from Allegheny General Hospital, Allegheny-Singer Research Institute and NIH grants DC002148 (GDE), DC02148 - 1651 (GDE), Al080935 (GDE). The funding bodies played no role in the design, collection, analysis, and interpretation of the data; in writing the manuscript; or in the decision to submit the manuscript for publication.

\section{Author details}

${ }^{1}$ Center for Genomic Sciences, Allegheny Singer Research Institute, Allegheny General Hospital, 320 East North Avenue, 11th Floor, South Tower, Pittsburgh, PA 15212, USA. ²Department of Biological Sciences, Carnegie Mellon University, Pittsburgh, PA, USA. ${ }^{3}$ Department of Microbiology and Immunology, Drexel University College of Medicine, Allegheny Campus, Pittsburgh, PA, USA. ${ }^{4}$ Department of Epidemiology, University of Michigan School of Public Health, Ann Arbor, MC, USA. ${ }^{5}$ Department of Pediatrics and Communicable Diseases, University of Michigan School of Public Health, Ann Arbor, MC, USA. ${ }^{6}$ Center for Childhood Infections, Seattle Children's Hospital Research Institute, Seattle, WA, USA. ${ }^{7}$ Department of Medicine, University at Buffalo, State University of New York, Buffalo, NY, USA. ${ }^{8}$ Department of Otolaryngology Head and Neck Surgery, Drexel University College of Medicine, Allegheny Campus, Pittsburgh, PA, USA.

Received: 17 October 2012 Accepted: 10 July 2013

Published: 17 July 2013

\section{References}

1. Tettelin H, Masignani V, Cieslewicz MJ, Donati C, Medini D, Ward NL, Angiuoli SV, Crabtree J, Jones AL, Durkin AS, Deboy RT, Davidsen TM, Mora M, Scarselli M, YRos MI, Peterson JD, Hauser CR, Sundaram JP, Nelson WC, Madupu R, Brinkac LM, Dodson RJ, Rosovitz MJ, Sullivan SA, Daugherty SC, Haft DH, Selengut J, Gwinn ML, Zhou L, Zafar N, et al: Genome analysis of multiple pathogenic isolates of Streptococcus agalactiae: implications for the microbial "pan-genome". Proc Natl Acad Sci U S A 2005, 102:13950-13955.

2. Hogg JS, Hu FZ, Janto B, Boissy R, Hayes J, Keefe R, Post JC, Ehrlich GD: Characterization and modeling of the Haemophilus influenzae core and supragenomes based on the complete genomic sequences of $\mathrm{Rd}$ and 12 clinical nontypeable strains. Genome Biol 2007, 8:R103.

3. Hiller NL, Janto B, Hogg JS, Boissy R, Yu S, Powell E, Keefe R, Ehrlich NE, Shen K, Hayes J, Barbadora K, Klimke W, Dernovoy D, Tatusova T, Parkhill J, Bentley SD, Post JC, Ehrlich GD, Hu FZ: Comparative genomic analyses of seventeen Streptococcus pneumoniae strains: insights into the pneumococcal supragenome. J Bacteriol 2007, 189:8186-8195.

4. Donati C, Hiller NL, Tettelin H, Muzzi A, Croucher NJ, Angiuoli SV, Oggioni M, Dunning Hotopp JC, Hu FZ, Riley DR, Covacci A, Mitchell TJ, Bentley SD, Kilian M, Ehrlich GD, Rappuoli R, Moxon ER, Masignani V: Structure and dynamics of the pan-genome of Streptococcus pneumoniae and closely related species. Genome Biol 2010, 11:R107.

5. Boissy R, Ahmed A, Janto B, Earl J, Hall BG, Hogg JS, Pusch GD, Hiller LN, Powell E, Hayes J, Yu S, Kathju S, Stoodley P, Post JC, Ehrlich GD, Hu FZ: Comparative supragenomic analyses among the pathogens Staphylococcus aureus, Streptococcus pneumoniae, and Haemophilus influenzae using a modification of the finite supragenome model. BMC Genomics 2011, 12:187.

6. Davie JJ, Earl J, de Vries SP, Ahmed A, Hu FZ, Bootsma HJ, Stol K, Hermans PW, Wadowsky RM, Ehrlich GD, Hays JP, Campagnari AA: Comparative analysis and supragenome modeling of twelve Moraxella catarrhalis clinical isolates. BMC Genomics 2011, 12:70. 
7. Ahmed A, Earl J, Retchless A, Hillier SL, Rabe LK, Cherpes TL, Powell E, Janto B, Eutsey R, Hiller NL, Boissy R, Dahlgren ME, Hall BG, Costerton JW, Post JC, Hu FZ, Ehrlich GD: Comparative Genomic Analyses of 17 Clinical Isolates of Gardnerella vaginalis Provide Evidence of Multiple Genetically Isolated Clades Consistent with Subspeciation into Genovars. J Bacterio/ 2012, 194:3922-3937.

8. Borneman AR, McCarthy JM, Chambers PJ, Bartowsky EJ: Comparative analysis of the Oenococcus oeni pan genome reveals genetic diversity in industrially-relevant pathways. BMC Genomics 2012, 13:373.

9. He M, Sebaihia M, Lawley TD, Tabler RA S, Dawson LF, Martin MJ, Holt KE, Seth-Smith HM, Quail MA, Rance R, Brooks K, Churcher C, Harris D, Bentley SD, Burrows C, Clark L, Corton C, Murray V, Rose G, Thurston S, van Tonder A, Walker D, Wren BW, Dougan G, Parkhill J: Evolutionary dynamics of Clostridium difficile over short and long time scales. Proc Natl Acad Sci US A 2010, 107:7527-7532.

10. Conlan S, Mijares LA, Comp Seq Program N, Becker J, Blakesley RR, Bouffard GG, Brooks S, Coleman HL, Gupta J, Gurson N, Park M, Schmidt B, Thomas PJ, Young A, Otto M, Kong HH, Murray PR, Segre JA: Staphylococcus epidermidis pan-genome sequence analysis reveals diversity of skin commensal and hospital infection-associated isolates. Genome Biol 2012, 13:R64.

11. Ehrlich GD, Hu FZ, Shen K, Stoodley P, Post JC: Bacterial Plurality as a General Mechanism Driving Persistence in Chronic Infections. Clin Orthop Relat Res 2005, 437:20-24.

12. Ehrlich GD, Ahmed A, Earl J, Hiller NL, Costerton JW, Stoodley P, Post JC, DeMeo P, Hu FZ: The distributed genome hypothesis as a rubric for understanding evolution in situ during chronic bacterial biofilm infectious processes. FEMS Immunol Med Microbiol 2010, 59:269-279.

13. Shen K, Wang X, Post JC, Ehrlich GD: Molecular and Translational Research Approaches for the study of Bacterial Pathogenesis in Otitis Media. In Evidence-based Otitis Media. 2nd edition. Edited by Rosenfeld R, Bluestone CD. Hamilton: B.C. Decker Inc; 2003:91-119.

14. Rasko DA, Rosovitz MJ, Myers GS, Mongodin EF, Fricke WF, Gajer P Crabtree J, Sebaihia M, Thomson NR, Chaudhuri R, Henderson IR, Sperandio V, Ravel J: The pangenome structure of Escherichia coli: comparative genomic analysis of $\mathrm{E}$. coli commensal and pathogenic isolates. J Bacteriol 2008, 190:6881-6893.

15. Touchon M, Hoede $C$, Tenaillon $O$, Barbe $V$, Baeriswyl $S$, Bidet $P$, Bingen $E_{\iota}$ Bonacorsi S, Bouchier C, Bouvet O, Calteau A, Chiapello H, Clermont O, Cruveiller S, Danchin A, Diard M, Dossat C, Karoui ME, Frapy E, Garry L, Ghigo JM, Gilles AM, Johnson J, Le Bouguénec C, Lescat M, Mangenot S, Martinez-Jéhanne V, Matic I, Nassif X, Oztas S, et al: Organised genome dynamics in the Escherichia coli species results in highly diverse adaptive paths. PLoS Genet 2009, 5:e1000344.

16. Buchinsky FJ, Forbes ML, Hayes JD, Shen K, Ezzo S, Compliment J, Hogg J, Hiller NL, Hu FZ, Post JC, Ehrlich GD: Virulence phenotypes of low-passage clinical isolates of nontypeable Haemophilus influenzae assessed using the chinchilla laniger model of otitis media. BMC Microbio 2007, 7:56.

17. Forbes ML, Horsey E, Hiller NL, Buchinsky FJ, Hayes JD, Compliment JM, Hillman T, Ezzo S, Shen K, Keefe R, Barbadora K, Post JC, Hu FZ, Ehrlich GD: Strain-specific virulence phenotypes of Streptococcus pneumoniae assessed using the Chinchilla laniger model of otitis media. PLOS One 2008, 3:e1969.

18. Hall-Stoodley L, Nistico L, Sambanthamoorthy K, Dice B, Nguyen D, Mershon WJ, Johnson C, Hu FZ, Stoodley P, Ehrlich GD, Post JC: Characterization of biofilm matrix, degradation by DNase treatment and evidence of capsule downregulation in Streptococcus pneumoniae clinical isolates. BMC Microbiol 2008, 8:173.

19. Ehrlich GD, Hiller NL, Hu FZ: What makes pathogens pathogenic. Genome Biol 2008, 9:225

20. Schwarz S, Morelli G, Kusecek B, Manica A, Balloux F, Owen RJ, Graham DY, van der Merwe S, Achtman M, Suerbaum S: Horizontal versus familia transmission of Helicobacter pylori. PLoS Pathog 2008, 4:e1000180.

21. Hiller NL, Ahmed A, Powell E, Martin DP, Eutsey R, Earl J, Janto B, Boissy RJ, Hogg J, Barbadora K, Sampath R, Lonergan S, Post JC, Hu FZ, Ehrlich GD: Generation of genic diversity among Streptococcus pneumoniae strains via horizontal gene transfer during a chronic polyclonal pediatric infection. PLoS Pathog 2010, 6:e1001108.

22. MacNeil JR, Cohn AC, Farley M, Mair R, Baumbach J, Bennett N, Gershman K, Harrison LH, Lynfield R, Petit S, Reingold A, Schaffner W, Thomas A, Coronado F, Zell ER, Mayer LW, Clark TA, Messonnier NE: Current epidemiology and trends in invasive Haemophilus influenzae disease-United States, 1989-2008. Clin Infect Dis 2011, 53:1230-1236.

23. Agrawal A, Murphy TF: Haemophilus Influenzae infections in the $\mathbf{H}$. influenza type b conjugate vaccine era. J Clin Microbiol 2011, 49:3728-3732

24. Döring G, Parameswaran IG, Murphy TF: Differential adaptation of microbial pathogens to airways of patients with cystic fibrosis and chronic obstructive pulmonary disease. FEMS Microbiol Rev 2011, 35:124-146.

25. Tsang RS, Sill ML, Skinner SJ, Law DK, Zhou J, Wylie J: Characterization of invasive Haemophilus influenzae disease in Manitoba, Canada, 2000-2006: invasive disease due to non-type b strains. Clin Infect Dis 2007, 44:1611-1614.

26. Shuel M, Law D, Skinner S, Wylie J, Karlowsky J, Tsang RS: Characterization of nontypeable Haemophilus influenzae collected from respiratory infections and invasive disease cases in Manitoba, Canada. FEMS Immunol Med Microbiol 2010, 58:277-284.

27. Kelly L, Tsang RS, Morgan A, Jamieson FB, Ulanova M: Invasive disease caused by Haemophilus influenzae type a in Northern Ontario First Nations communities. J Med Microbiol 2011, 60:384-390.

28. Fleischmann RD, Adams MD, White O, Clayton RA, Kirkness EF, Kerlavage AR, Bult CJ, Tomb JF, Dougherty BA, Merrick JM, McKenney K, Sutton G, FitzHugh W, Fields C, Gocayne JD, Soctt J, Shirley R, Liu L, Glodek A, Kelley JM, Weidman JF, Phillips CA, Spriggs T, Hedblom E, Cotton MD, Utterback TR, Hanna MC, Nguyen DT, Saudek DM, Brandon RC, et al: Whole-genome random sequencing and assembly of Haemophilus influenzae Rd. Science 1995, 269:496-512.

29. Erwin AL, Nelson KL, Mhlanga-Mutangadura T, Bonthuis PJ, Geelhood JL, Morlin G, Unrath WC, Campos J, Crook DW, Farley MM: Characterization of genetic and phenotypic diversity of invasive nontypeable Haemophilus influenzae. Infect Immun 2005, 73:5853-5863.

30. Harrison A, Dyer DW, Gillaspy A, Ray WC, Mungur R, Carson MB, Zhong H, Gipson J, Gipson M, Johnson LS, Lewis L, Bakaletz LO, Munson RS Jr: Genomic sequence of an otitis media isolate of nontypeable Haemophilus influenzae: comparative study with $\mathrm{H}$. influenzae serotype $\mathrm{d}$, strain KW20. J Bacteriol 2005, 187:4627-4636.

31. Haemophilus Influenzae 10810 genome sequencing project. http://www.ncbi. nlm.nih.gov/genome/165?project_id=86647.

32. Sauver JL, Marrs C, Foxman B, Somsel P, Madera R, Gilsdorf JR: Risk factors for otitis media and carriage of multiple strains of Haemophilus influenzae and Streptococcus pneumonia. Emerg Infect Dis 2000, 6:622-630.

33. Musser JM, Barenkamp SJ, Granoff DM, Selander RK: Genetic relationships of serologically nontypeable and serotype b strains of Haemophilus influenza. Infect Immun 1986, 52:183-191.

34. Murphy TF, Lesse AJ, Kirkham C, Zhong H, Sethi S, Munson RS Jr: A clonal group of nontypeable Haemophilus influenzae with two IgA proteases is adapted to infection in chronic obstructive pulmonary disease. PLoS One 2011, 6(10), E25923.

35. Fung WW, O'Dwyer CA, Sinha S, Brauer AL, Murphy TF, Kroll JS, Langford PR: Presence of copper-and zinc-containing superoxide dismutase in commensal H. influenzae isolates. J Clin Microbiol 2006, 44:4222-4226.

36. Shen K, Antalis P, Gladitz J, Sayeed S, Ahmed A, Yu S, Hayes J, Johnson S, Dice B, Dopico R, Keefe R, Janto B, Chong W, Goodwin J, Wadowsky RM, Erdos G, Post JC, Ehrlich GD, Hu FZ: Identification, distribution, and expression of novel genes in 10 clinical isolates of nontypeable Haemophilus influenza. Infect Immun 2005, 73:3479-3491.

37. Aziz RK, Bartels D, Best AA, DeJongh M, Disz T, Edwards RA, Formsma K, Gerdes S, Glass EM, Kubal M, Meyer F, Olsen GJ, Olson R, Osterman AL, Overbeek RA, McNeil LK, Paarmann D, Paczian T, Parrello B, Pusch GD, Reich C, Stevens R, Vassieva O, Vonstein V, Wilke A, Zagnitko O: The RAST Server: rapid annotations using subsystems technology. BMC Genomics 2008, 9:75

38. Pearson WR, Lipman DJ: Improved tools for biological sequence comparison. Proc Natl Acad Sci USA 1988, 1988(85):2444-2448.

39. Sambrook J, Russell DW: Molecular Cloning: A Laboratory Manual, Volume 1. Cold Spring Harbor, New York: Cold Spring Harbor Laboratory Press: 2001:2344.

40. Ausubel FM: Current protocols in molecular biology, Volume 1. (2.4.3). Hoboken, New Jersey: Wiley; 1991

41. Paradis E, Claude J, Strimmer K: APE: analyses of phylogenetics and evolution in R language. Bioinformatics 2004, 20:289-290. 
42. FigTree v1.3.1. available at http://tree.bio.ed.ac.uk/software/figtree/.

43. Lacross NC, Marrs CF, Patel M, Sandstedt SA, Gilsdorf JR: High genetic diversity of nontypeable Haemophilus influenzae isolates from two children attending a day care center. J Clin Microbiol 2008, 46:3817-3821.

44. Gerdes K, Rasmussen PB, Molin S: Unique type of plasmid maintenance function: postsegregational killing of plasmid-free cells. Proc Natl Acad Sci USA 1986, 83:3116-3120.

45. Wang WF, Cheng X, Molineux IJ: Isolation and Identification of fxsA, an Escherichia coli gene that can suppress $F$ exclusion of bacteriophage T7. J Mol Biol 1999, 292:485-499.

46. Sandstedt SA, Zhang L, Patel M, Marrs CF, Gilsdorf JR: Comparison of laboratory-based and phylogenetic methods to distinguish between Haemophilus influenza and H. haemolyticus. J Microbioal Methods 2008, 75:369-371

47. McCrea KW, Xie J, LaCross N, Patel M, Mukundan M, Murphy TF, Marrs CF, Gilsdorf JR: Relationships of non-typeable Haemophilus influenza with hemolytic and non-hemolytic Haemophilus haemolyticus. J Clin Microbiol 2008, 46:406-416.

48. Murphy TF, Brauer AL, Sethi S, Kilian M, Cai X, Lesse AJ: Haemophilus haemolyticus: a human respiratory tract commensal to be dintinguished from Haemophilus influenza. J Infect Dis 2007, 195:81-89.

49. Hiller NL, Eutsey RA, Powell E, Earl JP, Janto B, Martin DP, Dawid S, Ahmed A, Longwell MJ, Dahlgren ME, Ezzo S, Tettelin H, Daugherty SC, Mitchell TJ, Hillman TA, Buchinsky FJ, Tomasz A, de Lencastre H, Sá-Leão R, Post JC, Hu FZ, Ehrlich GD: Differences in genotype and virulence among four multidrug-resistant Streptococcus pneumoniae isolates belonging to the PMEN1 clone. PLoS One 2011, 6:e28850.

50. Hu FZ, Eutsey R, Ahmed A, Frazao N, Powell E, Hiller NH, Hillman T, Buchinsky FJ, Boissy R, Janto B, Kress-Bennett JM, Longwell M, Suzanne E, Post JC, Tomasz A, Ehrlich GD: In vivo capsular switch in Streptococcus pneumoniae. PLoS One 2012, 7(11):e47983.

51. Anderson R, Wang X, Briere EC, Katz LS, Cohn AC, Clark TA, Messonnier NE, Mayer LW: Haemophilus haemolyticus isolates causing clinical disease. J Clin Microbiol 2012, 50:2462-2465.

52. Wickert E, Machado MA, Lemos EG: Evaluation of the genetic diversity of Xylella fastidiosa strains from citrus and coffee hosts by singlenucleotide polymorphism markers. Phytopathology 2007, 97:1543-1549.

53. Mathee K, Narasimhan G, Valdes C, Qiu X, Matewish JM, Koehrsen M, Rokas A, Yandava CN, Engels R, Zeng E, Olavarietta R, Doud M, Smith RS, Montgomery P, White JR, Godfrey PA, Kodira C, Birren B, Galagan JE, Lory S: Dynamics of Pseudomonas aeruginosa genome evolution. Proc Natl Acad Sci U S A 2008, 105:3100-3105.

54. Mell JC, Shumilina S, Hall IM, Redfield RJ: Transformation of natural genetic variation into Haemophilus influenza genomes. PLoS Pathog 2011, 7(7):e1002151

55. Nistico L, Earl J, Hiller NL, Ahmed A, Retchless A, Janto B, Costerton JW, Hu FZ, Ehrlich GD: Using the Core and Supra Genomes to Determine Diversity and Natural Proclivities among Bacterial Strains. In Molecular Methods and Applications in Microbiology. Edited by Skovhus TL, Caffrey S, Hubert C. Norfolk, UK: Caister Academic Press; 2014. In Press.

doi:10.1186/1471-2164-14-484

Cite this article as: Eutsey et al:: Design and validation of a supragenome array for determination of the genomic content of Haemophilus influenzae isolates. BMC Genomics 2013 14:484.

\section{Submit your next manuscript to BioMed Central and take full advantage of:}

- Convenient online submission

- Thorough peer review

- No space constraints or color figure charges

- Immediate publication on acceptance

- Inclusion in PubMed, CAS, Scopus and Google Scholar

- Research which is freely available for redistribution

Submit your manuscript at www.biomedcentral.com/submit
Biomed Central 